\title{
INVIVO EVALUATION OF THE EFFECTS OF Allium sativum ON THE PHARMACOKINETIC PARAMETERS OF CIPROFLOXACIN AND ISONIAZID.
}

\author{
NDUKA S.0.1,2*, OKONTA J.M. ${ }^{2}$ AND ESIMONE C.0. ${ }^{3}$ \\ 1Department of Clinical Pharmacy and Pharmacy Management, Nnamdi Azikiwe University, Awka, Anambra State, Nigeria. \\ 2Department of Clinical Pharmacy and Pharmacy Management, University Of Nigeria Nsukka 410001,Enugu State, Nigeria. \\ ${ }^{3}$ Department of Pharmaceutics, Nnamdi Azikiwe University, Awka, Anambra State, Nigeria. \\ *Corresponding Author: Email- odinduka@ymail.com
}

Received: October 02, 2011; Accepted: February 15, 2012

\begin{abstract}
-
Objective: The pharmacokinetic parameters of isoniazid and ciprofloxacin administered orally to garlic (Allium sativum) pretreated rats of both sex divided into four groups of five rats per group was determined.

Methods: Two groups received ciprofloxacin $20 \mathrm{mg} / \mathrm{kg}$ and Isoniazid $15 \mathrm{mg} / \mathrm{kg}$ respectively while the other groups received garlic extract for 10 days followed by the administration of ciprofloxacin or Isoniazid on the 11th day. Blood samples were collected from each group at different time interval and plasma concentrations of the drugs determined spectrophotometrically. The pharmacokinetic parameters were determined using the non-compartmental method as implemented in win Nonlin. Secondly, the effect of Allium sativum on the lung penetration of the drugs at same dose range was determined also in rats.

Results: Garlic significantly increased the AUC of ciprofloxacin from $119.00 \pm 0.962$ to $256.32 \pm 0.680$ and decreased $V_{d}$ from $1.13 \pm 0.172$ to $0.90 \pm 0.009$ and $\mathrm{CL}$ from $0.16 \pm 0.011$ to $0.062 \pm 0.001$. The AUC of INH was also increased from $491.84 \pm 56.765$ to $574.04 \pm 50.600$ and $\mathrm{CL}$ was significantly decreased from $0.02 \pm 0.007$ to $0.01 \pm 0.003$ where as $V_{d}$ showed little or no change, $(0.397 \pm 0.009 / 0.42 \pm 0.143)$. Garlic increased the maximum concentration of ciprofloxacin achieved in the lung fluid and the time to attain this concentration was delayed, while the maximum concentration of INH achieved in the presence and absence of the herb showed no difference though, the time to attain this concentration were delayed.
\end{abstract}

Conclusion: Our findings therefore suggested that the co-administration of garlic with ciprofloxacin or Isoniazid may pose a negative clinical implication of increased drug toxicity and/or adverse effects.

Keywords- pharmacokinetics, garlic, ciprofloxacin, Isoniazid, interaction, in vivo, lung, penetration.

Citation: Nduka S.O., Okonta J.M. and Esimone C.O. (2012) Invivo Evaluation of the Effects of Allium sativum on the Pharmacokinetic Parameters of Ciprofloxacin and Isoniazid. International Journal of Drug Discovery, ISSN: 0975-4423 \& E-ISSN: 0975-914X, Volume 4, Issue 1, pp.-123-127.

Copyright: Copyright@2012 Nduka S.O., et al. This is an open-access article distributed under the terms of the Creative Commons Attribution License, which permits unrestricted use, distribution, and reproduction in any medium, provided the original author and source are credited.

\section{Introduction}

The use of herbal supplements as natural remedies is popular these days. Many of these herbal supplements can interact with prescription and non-prescription medications sometimes with severe consequences. For instance, one report found that garlic reduced the plasma saquinavir level [1]. Similarly, an extract of green tea taken by healthy women with a meal inhibited the absorption of non-heme iron (e.g., the form of iron in plant foods) by $26 \%$ [2] and consuming large amount of these substances while taking theophylline, increases the risk of drug toxicity.

Garlic is a bulb of a lily-like plant belonging to the same family as onions and has been used as herbal remedy for some common ailments. It has been shown to promote wound healing and prevent cold and influenza. Garlic produces significant reduction in total cholesterol and triglyceride [3] and effective in hypertension reduc- tion [4]. Some also have it that garlic may reduce the risk of cancers of the stomach and colon [5].

Several preclinical studies have shown that garlic constituents can modulate the activities of various drug metabolizing enzymes. Fresh garlic extracts and commercially available garlic products were shown to inhibit cytochrome P450 isoforms $2 \mathrm{C} 9^{*} 1,2 \mathrm{C} 19$, and 3A4 during metabolism of a marker substrate [6]. Garlic oil and its three allyl sulfide components administered for six weeks have been shown to lead to enhanced activities and increased expression of CYP 3A1, 2B1 and 1A1 in the hepatic detoxification system of rats [7]. In a study in healthy volunteers, a 3-week administration of a garlic supplement decreased plasma concentrations of the protease inhibitor saquinavir by about $50 \%$ [1]. Similarly, garlic formulations have been shown to inhibit human CYP3A4 mediated metabolism and P-glycoprotein mediated transport in vitro [7]. 
Isoniazid, a drug commonly used in the treatment of tuberculosis is readily absorbed from the gastrointestinal tract [8]. Peak concentrations of about 3 to 7 micrograms $/ \mathrm{ml}$ appear in blood 1-2 hours after an oral dose of $300 \mathrm{mg}[8]$. It is not considered to bound appreciably to plasma proteins and diffuses into all body tissues and fluids [9]. The primary metabolic route is the acetylation of isoniazid by $\mathrm{N}$ acetyltransferase found in the liver and small intestine [8].

Ciprofloxacin is a member of the fluoroquinolone group of antibiotics. They are generally active against gram negative and gram positive organisms. Ciprofloxacin is rapidly and well absorbed from the gastrointestinal tract [8]. Its oral bioavailability is approximately $70 \%$ and plasma protein binding ranges from $20-40 \%$ and it is widely distributed in the body and tissue penetration is generally good [8]. Its metabolism is principally by the liver and eliminated through renal and biliay excretion [8].

Garlic which is commonly used as food additives have been shown to contain quercetin [10], a flavonoid which may interact with some medications. Therefore, as part of the on-going effort to establish interactions between supplements and drugs, this study was designed to find out the impact/effect of garlic extract pretreatment on the bioavailability and lung penetration of Isoniazid and ciprofloxacin using animal model.

\section{Materials and Methods}

Garlic was purchased from orba market in Nsukka, Enugu state, Nigeria and ciprofloxacin tablets, Ciprotab (Fidson, Nigeria) and Isoniazid tablets (Mancare Pharmaceutical, India) were purchased from a registered pharmacy in Enugu state, Nigeria. Ciprofloxacin hydrochloride powder and Isoniazid powder were obtained as gifts.

\section{Animals}

Albino rats $(175-225 \mathrm{~g})$ of both sexes were obtained from the Faculty of Veterinary Medicine, University of Nigeria, Nsukka and housed according to their sex. They were kept under close observation for one week before the commencements of the experiment to enable them acclimatize.

\section{Preparation of samples}

Garlic was collected, separated into cloves and then, dried scales removed. $5 \mathrm{~g}$ were weighed and extracted in $20 \mathrm{ml}$ of water, then filtered. The filtrate of the extracts was used for the experiment.

\section{Treatment of animals}

The albino rats of either sex were divided into four groups (A-D) of 5 animals per group. Animals in Group A were administered Ciprofloxacin orally at a dose rate of $20 \mathrm{mg} / \mathrm{kg}$ body weight. Group B received $15 \mathrm{mg} / \mathrm{kg}$ of Isoniazid orally. Group $C$ were fed with $2 \mathrm{ml} / \mathrm{kg}$ of garlic extract for 10 days. On day 11, they received the garlic extract followed by $20 \mathrm{mg} / \mathrm{kg}$ of ciprofloxacin as in group A. Group D received $2 \mathrm{ml} / \mathrm{kg}$ garlic extract for 10 days followed by $15 \mathrm{mg} / \mathrm{kg}$ of Isoniazid in day 11 , concomitantly with $2 \mathrm{ml} / \mathrm{kg}$ of garlic extracts.

Blood samples were collected from all the animals across the groups, through eye vein puncture using capillary tubes into EDTA bottles at time intervals of $0,0.5,1,2,5,8,12$,and 24 hours. The blood samples collected were centrifuged at $3000 \mathrm{rpm}$ for $10 \mathrm{~min}$ for plasma separation. The plasma samples were refrigerated until assayed.

In the determination of the effects of herb on drug penetration into the lungs, albino rats of either sex (175-225g) were divided into four groups (A-D) of 20 animals per group. Animals in Group A were administered Ciprofloxacin orally at a dose of $20 \mathrm{mg} / \mathrm{kg}$ body weight. Group B received $15 \mathrm{mg} / \mathrm{kg}$ of Isoniazid orally. Group C received $2 \mathrm{ml} / \mathrm{kg}$ garlic extract for 10 days followed by $20 \mathrm{mg} / \mathrm{kg}$ of ciprofloxacin in day 11 concomitantly with $2 \mathrm{ml} / \mathrm{kg}$ of garlic extracts. Group D received $2 \mathrm{ml} / \mathrm{kg}$ of garlic extract for 10 days followed by concomitant administration of the extract and Isoniazid as in Group B on the 11th day. At 1, 3, 8, and $12 \mathrm{hr}$, following the oral administration of the drugs, and herb and drug as the case was, four animals were killed with chloroform from each group at every time interval and the lungs collected. Blood was also collected from the lung area and the plasma collected through centrifugation. The lungs were rinsed in non- bacteriostatic saline to eliminate contaminating blood. They were later homogenised individually in phosphate buffered saline ( $\mathrm{pH}$ 6.2). All specimens after centrifugation were stored in a refrigerator until assayed.

Isoniazid was extracted and analysed by the method of Eidus and Hamanan Singh 1971 and 1974 [11], protein free samples were prepared by mixing each sample with 2 volumes of methanol and the solvent evaporated out. The supernatant was mixed with $0.04 \%$ trans-cinnamaldehyde solution in absolute ethanol and absorbance measured at $314 \mathrm{~nm}$ using the spectrophotometer (Sp-6-450 UVI Vis Pye Unicam).

On the other hand, ciprofloxacin concentration was measured with UV-spectrophotometer using the method developed by De et al [12]. Using this method, the plasma samples were deproteinised using isopropyl alcohol and the absorbance measured at $342 \mathrm{~nm}$. Different pharmacokinetic parameters were determined using noncompartmental model as implemented in winNonlin pharmacokinetic programs version 5.0, (Pharsight Corporation, Mountain View Califonia). Time taken for drugs to attain maximal plasma concentration $\left(T_{\max }\right)$, maximal drug plasma concentration $\left(\mathrm{C}_{\max }\right)$, last measurable drug plasma concentration( $\mathrm{C}_{\text {last}}$ ), area under curve from the time of dosing to the time of the last observation (AUC), area under moment curve from the time of dosing to the time of last measurable concentration (AUMC), mean residence time (MRT), terminal half-life $\left(\mathrm{t}_{1 / 2}\right)$, volume of distribution based on the terminal phase $\left(\mathrm{V}_{\mathrm{d}}\right)$, and total body clearance $(\mathrm{Cl})$ were determined.

\section{Result}

The pharmacokinetic parameters of Isoniazid administered alone and following garlic pretreatment are shown in [Table-1] and the concentration-time graph shown in [Fig-1]. In the presence of garlic, INH maximum concentration $\left(\mathrm{C}_{\max }\right)$ of $74.58 \pm 6.746 \mu \mathrm{g} / \mathrm{ml} \mathrm{oc-}$ curred at $0.67 \mathrm{hr}$ while in the group that received garlic alone, INH maximum concentration of $49.47 \pm 1.630 \mu \mathrm{g} / \mathrm{ml}$ occurred at $0.83 \mathrm{hr}$. This difference in maximum concentration was significant $(p<0.05)$ while, the difference in time to attain maximum concentration $\left(t_{\max }\right)$ was not significant. There was no significant difference between the AUC obtained when INH was administered alone $(491.84 \pm 16.765 \mu \mathrm{g} / \mathrm{ml} / \mathrm{hr})$ and that obtained in garlic pretreated group $(574.04 \pm 20.690 \mu \mathrm{g} / \mathrm{ml} / \mathrm{hr})$. In the same way, AUMC in the presence and absence of garlic $\left(5224.45 \pm 43.157 \mu \mathrm{g} / \mathrm{ml} / \mathrm{hr}^{2}\right.$ and $4583.68 \pm 69.382 \mu \mathrm{g} / \mathrm{ml} / \mathrm{hr}^{2}$ respectively) showed no significant difference. Half life also showed no significant difference. Meanwhile, mean resident time (MRT) and volume of distribution showed little or no change between the two groups.

The pharmacokinetic parameters of ciprofloxacin alone and following garlic pretreatment in albino rats are presented in [Table-2] and the graph used to determine the pharmacokinetic parameters using 
WinNonlin pharmacokinetic program shown in [Fig-2]. Pretreatment with garlic resulted in a significant increase in ciprofloxacin maximum concentration $\left(C_{\max }\right)(p<0.05)$ from $33.12 \pm 0.309 \mu \mathrm{g} / \mathrm{ml}$ to $20.98 \pm 1.161 \mu \mathrm{g} / \mathrm{ml}$ and no change in the time to reach maximum concentration $\left(t_{\max }\right)$. Pretreatment with garlic also, produced significant increase in area Under Curve (AUC), Area Under Moment Curve (AUMC), Mean resident time (MRT), clearance $(\mathrm{Cl})$ and the terminal half life $\left(t_{1} / 2\right)$, while there were no significant change $(p>$ $0.05)$ in the volume of distribution $\left(\mathrm{V}_{\mathrm{d}}\right)$ and $\mathrm{C}_{\text {last. }}$ However, there was about $20.35 \%$ decrease in the volume of distribution in the garlic pretreated group.

Table 1- Comparative Pharmacokinetics of INH Administered Orally $(15 \mathrm{mg} / \mathrm{Kg})$ Alone and INH With Garlic Treated Rat (Mean \pm Sem). $(N=5)$

\begin{tabular}{|lcc|}
\hline PARAMETER & INH ALONE & INH + GAR \\
\hline Tmax $(\mathrm{hr})$ & $0.83 \pm 0.167$ & $0.67 \pm 0.167$ \\
Cmax $(\mu \mathrm{g} / \mathrm{ml})$ & $49.47 \pm 1.63$ & $74.58 \pm 6.746^{*}$ \\
Clast $(\mu \mathrm{g} / \mathrm{ml})$ & $12.08 \pm 4.597$ & $14.47 \pm 0.283$ \\
AUC $(\mu / \mathrm{hr} / \mathrm{ml})$ & $491.84 \pm 56.765$ & $574.04 \pm 50.600$ \\
$\mathrm{t} 1 / 2(\mathrm{hr})$ & $15.55 \pm 5.688$ & $21.97 \pm 10.950$ \\
$\mathrm{~V}_{\mathrm{d}}(\mathrm{ml} / \mathrm{kg})$ & $0.397 \pm 0.009$ & $0.42 \pm 0.143$ \\
$\mathrm{Cl}(\mathrm{ml} / \mathrm{kg} / \mathrm{hr})$ & $0.02 \pm 0.007$ & $0.01 \pm 0.003^{*}$ \\
$\mathrm{AUMC}\left(\mu \mathrm{g} / \mathrm{ml} / \mathrm{hr}^{2}\right)$ & $4583.68 \pm 69.382$ & $5224.45 \pm 43.157$ \\
$\mathrm{MRT}(\mathrm{hr})$ & $9.17 \pm 0.655$ & $9.22 \pm 0.835$ \\
\hline
\end{tabular}

$n$ is number of animal per group,

${ }^{*}<0.05$ significant to the parameter of INH alone.

CIP means ciprofloxacin, GAR means garlic. Tmax is time taken for drugs to attain maximal plasma concentration. Cmax is maximal drug plasma concentration Clast is last measurable drug plasma concentration AUC is area under curve from the time of dosing to the time of the last observation AUMC is area under moment curve from the time of dosing to the time of last measurable concentration MRT is mean residence time $t 1 / 2$ is terminal half-life $V d$ is volume of distribution based on the terminal phase $\mathrm{Cl}$ is total body clearance.

Table 2- Comparative Pharmacokinetics of Ciprofloxacin Administered Orally $(20 \mathrm{mg} / \mathrm{Kg})$ Alone and Ciprofloxacin with Garlic Treated Rats

\begin{tabular}{|lcc|}
\hline PARAMETER & CIP ALONE & ClP + GAR \\
\hline$T_{\max }(\mathrm{hr})$ & $0.83 \pm 0.167$ & $0.83 \pm 0.167$ \\
$\mathrm{C}_{\max }(\mu \mathrm{g} / \mathrm{ml})$ & $20.98 \pm 1.161$ & $33.12 \pm 0.309^{*}$ \\
$\mathrm{C}_{\text {last }}(\mu \mathrm{g} / \mathrm{ml})$ & $0.95 \pm 0.436$ & $3.94 \pm 0.110$ \\
AUC $(\mu \mathrm{g} / \mathrm{ml} / \mathrm{hr})$ & $119.00 \pm 4.947$ & $256.32 \pm 0.680^{*}$ \\
$\mathrm{t} / \mathrm{hr})$ & $5.06 \pm 0.962$ & $9.66 \pm 0.116^{*}$ \\
$\mathrm{~V}_{\mathrm{d}}(\mathrm{ml} / \mathrm{kg})$ & $1.13 \pm 0.172$ & $0.90 \pm 0.009$ \\
$\mathrm{Cl}(\mathrm{ml} / \mathrm{kg} / \mathrm{hr})$ & $0.16 \pm 0.011$ & $0.062 \pm 0.001^{*}$ \\
AUMC $(\mu \mathrm{g} / \mathrm{ml} / \mathrm{hr} 2)$ & $711.19 \pm 50.312$ & $2204.007 \pm 19.497^{*}$ \\
MRT $(\mathrm{hr})$ & $5.91 \pm 0.217$ & $8.61 \pm 0.083^{*}$ \\
\hline
\end{tabular}

(mean \pm SEM).

$n$ is number of animal per group,

* $<0.05$ significant to the parameter of CIP alone.

CIP means ciprofloxacin, GAR means garlic. Tmax is time taken for drugs to attain maximal plasma concentration.Cmax is maximal drug plasma concentration Clast is last measurable drug plasma concentration AUC is area under curve from the time of dosing to the time of the last observation AUMC is area under moment curve from the time of dosing to the time of last measurable concentration MRT is mean residence time $t 1 / 2$ is terminal half-life $\mathrm{Vd}$ is volume of distribution based on the terminal phase $\mathrm{Cl}$ is total body clearance.

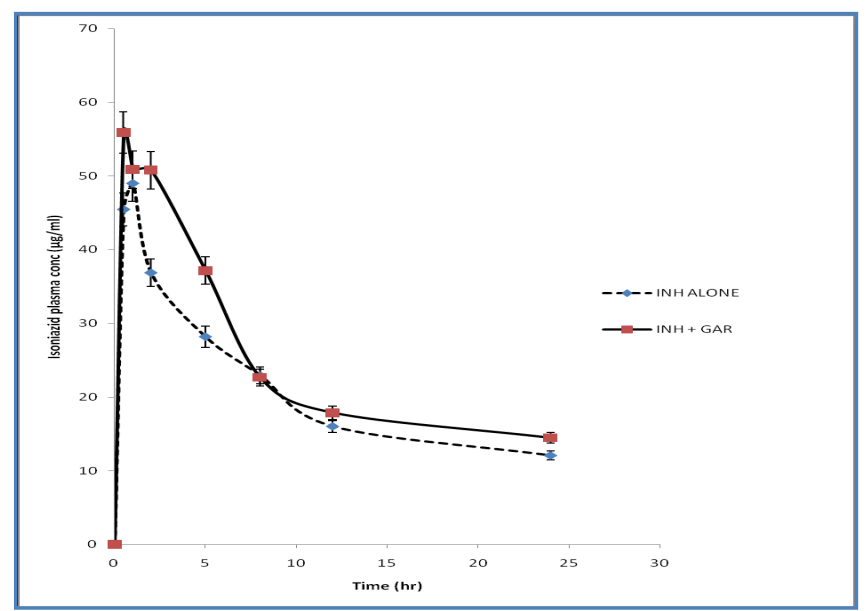

Fig. 1- Plasma Concentration-Time Profile of INH in Garlic Treated Rats Following a Single Oral Administration

On the penetration effects studies, Ciprofloxacin peak lung plasma concentration of $6.48 \pm 1.938 \mu \mathrm{g} / \mathrm{ml}$ occurred at $8 \mathrm{hr}$ when ciprofloxacin was administered alone while its lung plasma maximum concentration of $27.97 \pm 1.339 \mu \mathrm{g} / \mathrm{ml}$ was achieved in $8 \mathrm{hr}$ in the presence of Garlic. This difference in maximum concentration was highly significant. Meanwhile, there were significant increases in the concentrations achieved at 1, 3, 8 and $24 \mathrm{hr}$ in the garlic treated rats compare to the group that received ciprofloxacin alone. In the lung fluid, ciprofloxacin maximum concentration of $3.90 \pm 1.296 \mu \mathrm{g} /$ $\mathrm{ml}$ occurred at $1 \mathrm{hr}$ when ciprofloxacin was administered alone whereas, in the presence of garlic, ciprofloxacin maximum concentration of $5.09 \pm 2.000 \mu \mathrm{g} / \mathrm{ml}$ occurred at $8 \mathrm{hr}$. The difference in both maximal concentration and time to attain maximal concentration were significant.

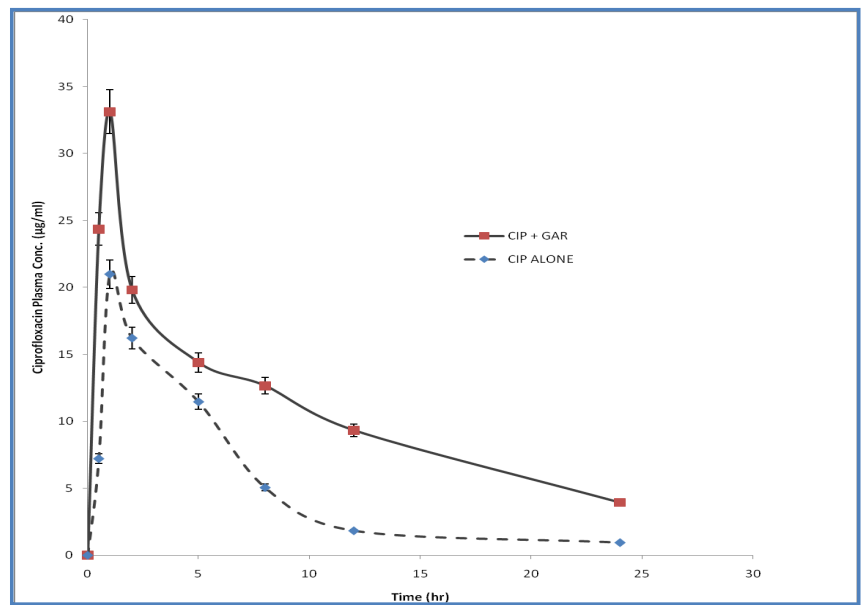

Fig. 2- Plasma Concentration-Time Profile Of Ciprofloxacin In Garlic Treated Rats Following A Single Oral Dose.

While significant differences were observed at $8 \mathrm{hrs}$ and $24 \mathrm{hrs}$ concentrations achieved in garlic treated group, no significant difference were observed in their $1 \mathrm{hr}$ and $3 \mathrm{hr}$ concentrations. The half life of ciprofloxacin in the lung plasma when administered alone 
was $3.00 \pm 0.123 \mathrm{hr}$ and the half life of ciprofloxacin in the presence of garlic was $2.88 \pm 0.212 \mathrm{hr}$ showing little or no difference. On the lung fluid level, ciprofloxacin half life of $41.81 \pm 0.418 \mathrm{hr}$ was achieved in the control group and $79.94 \pm 0.611 \mathrm{hr}$ was achieved in the garlic pretreated group.

The plasma AUC in the presence of garlic was significantly higher than the AUC obtained when ciprofloxacin was administered alone. Similarly, the AUC of ciprofloxacin obtained in the lung fluid in the presence of garlic, $108.75 \pm 0.875 \mu \mathrm{g} / \mathrm{ml} / \mathrm{hr}$ was significantly higher than that obtained when ciprofloxacin was administered alone $70.11 \pm 0.465 \mu \mathrm{g} / \mathrm{ml} / \mathrm{hr}$.

INH maximum concentration of $3.89 \pm 1.930 \mu \mathrm{g} / \mathrm{ml}$ was achieved in $3 \mathrm{hr}$ in the lung plasma when INH was administered alone while in the presence of garlic maximum concentration of $8.46 \pm 1.546 \mu \mathrm{g} / \mathrm{ml}$ was achieved in $1 \mathrm{hr}$. This difference was significant. The concentrations achieved at the different time intervals in garlic treated groups were significantly higher than those achieved when INH was administered alone except at the $8 \mathrm{hr}$ where the difference was not significant. In the lung fluid, INH maximum concentration of $4.37 \pm 1.572 \mu \mathrm{g} / \mathrm{ml}$ was achieved at $1 \mathrm{hr}$ when administered alone, while in the presence of garlic, maximum concentration of $4.05 \pm 0.141 \mu \mathrm{g} / \mathrm{ml}$ was achieved at $8 \mathrm{hr}$.

Garlic led to significant increase in INH concentration at $8 \mathrm{hr}$ and $24 \mathrm{hr}$ with no significant decrease at $1 \mathrm{hr}$ while there was little or no change at $3 \mathrm{hr}$. Significant difference was observed in lung plasma $\mathrm{INH}$ half life in the presence of garlic, $21.81 \pm 0.015 \mathrm{hr}$ compared to the group that received INH alone, $8.95 \pm 0.192 \mathrm{hr}$.

Table 3- Comparison of Mean Lung Plasma Levels of Ciprofloxacin and Isoniazid ( $\mu \mathrm{g} / \mathrm{MI})$ at Different Time Intervals following Oral Administration of Ciprofloxacin Alone $(20 \mathrm{mg} / \mathrm{Kg})$ and Isoniazid $(15 \mathrm{mg} / \mathrm{Kg})$ and with the Herb

\begin{tabular}{lcccc} 
TIME (hrs.) & CIP ALONE & INH ALONE & CIP + GAR & INH + GAR \\
\hline 1 & $0.16 \pm 3.102$ & $3.16 \pm 2.362$ & $4.78 \pm 2.562^{*}$ & $8.46 \pm 1.546^{*}$ \\
3 & $2.09 \pm 1.114$ & $3.89 \pm 1.930$ & $5.44 \pm 1.712^{*}$ & $6.19 \pm 2.392^{*}$ \\
8 & $6.48 \pm 1.938$ & $3.62 \pm 2.699$ & $27.97 \pm 1.339^{*}$ & $4.33 \pm 2.624$ \\
24 & $0.16 \pm 2.364$ & $0.65 \pm 1.434$ & $0.60 \pm 1.906$ & $3.58 \pm 3.021^{*}$ \\
\hline
\end{tabular}

(mean \pm SEM).

$(n=4)$

$n$ is number of animal killed per group at a particular time, * $<0.05$ significant to the parameter of CIP or INH alone.CIP means ciprofloxacin, GAR means garlic.

Table 4- Comparison of Mean Lung Fluid Levels of Isoniazid and Ciprofloxacin ( $\mu \mathrm{g} / \mathrm{MI})$ at Different Time Intervals Following Oral Administration of Isoniazid Alone $(15 \mathrm{mg} / \mathrm{Kg})$ and Ciprofloxacin Alone $(20 \mathrm{mg} / \mathrm{Kg})$ and in the Presence of Garlic.

\begin{tabular}{|lcccc|} 
TIME (hrs.) & CIP ALONE & INH ALONE & CIP + GAR & INH + GAR \\
\hline 1 & $3.90 \pm 1.296$ & $4.37 \pm 1.572$ & $3.76 \pm 1.304$ & $3.52 \pm 1.260$ \\
3 & $3.65 \pm 2.531$ & $3.60 \pm 0.309$ & $4.09 \pm 1.402$ & $3.70 \pm 1.940$ \\
8 & $2.91 \pm 1.504$ & $2.90 \pm 2.590$ & $5.09 \pm 2.000^{*}$ & $4.05 \pm 0.141^{\star}$ \\
24 & $2.60 \pm 0.962$ & $2.30 \pm 1.039$ & $4.16 \pm 0.328^{*}$ & $3.85 \pm 0.945^{*}$ \\
\hline
\end{tabular}

(mean \pm SEM)

$(n=4)$

$n$ is number of animal killed per group at a particular time, * $<0.05$ significant to the parameter of cip or INH alone. CIP means ciprofloxacin, GAR means garlic.

INH lung fluid half life was $27.90 \pm 0.535 \mathrm{hr}$ when INH was administered alone, $218.42 \pm 14.903 \mathrm{hr}$ in the presence of garlic. The AUC for lung plasma INH when administered alone, $54.55 \pm 0.855 \mu \mathrm{g} / \mathrm{ml} /$ $\mathrm{hr}$ was significantly lower than the AUC obtained in the presence of garlic, 108.11 \pm 0.718 . On the other hand, the AUC of INH obtained in the lung fluid in the presence of garlic $91.75 \pm 433 \mu \mathrm{g} / \mathrm{ml} / \mathrm{hr}$ was significantly higher than that obtained when INH was administered alone, $67.73 \pm 0.213 \mu \mathrm{g} / \mathrm{ml} / \mathrm{hr}$.

\section{Discussion}

In the present study, we showed that the co-administration of the herb, garlic influenced the pharmacokinetics of two commonly used antimicrobial drugs, Isoniazid (INH) and Ciprofloxacin in albino rats. On the effect of garlic on plasma ciprofloxacin pharmacokinetics, it was evident that garlic increased the extent and rate of ciprofloxacin absorption. The enhanced extent of absorption can be seen from the fact that ciprofloxacin maximal concentration (Cmax) and total Area under Curve (AUC) in garlic treated groups were significantly higher than those obtained when ciprofloxacin was administered alone. This enhanced absorption may be due to the ability of garlic to enhance gastric motility [13] and hence increased absorption. Increased gastrointestinal motility may facilitate drug absorption by thoroughly mixing intestinal contents thereby bringing the drug into more intimate contact with the mucosal surface [14].

The higher values of AUC, AUMC and MRT in garlic treated rats were indicative of enhanced systemic availability of ciprofloxacin and probable suppression of drug metabolizing activities of enzymes by garlic in the rats. The possible suppression of drug metabolizing activity of enzymes by garlic was further indicated by the longer half life in garlic treated group and hence a significant reduction in ciprofloxacin clearance. The metabolism of ciprofloxacin has been shown to be hepatic involving the CYP 450 enzymes mainly CYP IA2 [10] and garlic has been shown to inhibit the activities of hepatic CYP IA2 [15] decreasing the availability of such enzyme. Though not significant, the little change in the volume of distribution indicated that there may have been a slight change in the protein binding capacity of ciprofloxacin in the garlic treated group. That is, there may have been an enhanced plasma protein binding capacity of ciprofloxacin by garlic which resulted in decrease in the volume of distribution $(\mathrm{Vd})$.

Garlic also enhanced both rate and extent of INH absorption. There was an appreciable increase in maximum concentration (Cmax) and Tmax decreased in the garlic treated group which was indicative of enhanced absorption profile. Meanwhile, INH has been shown not to bind appreciably to plasma protein [9], and diffuses into all body tissues and fluids including the cerebrospinal fluid. Therefore, the little or no change in volume of distribution between the garlic treated group and the group that received INH alone probably, completely ruled out protein-binding interaction. The slight increases in AUC, AUMC and Cmax were indicative of enhanced absorption and systemic availability of Isoniazid in the presence of garlic. This again may be due to increased gastric motility caused by garlic [13]. Furthermore, since the acetylation of $\mathrm{INH}$ is mediated through the $\mathrm{N}$-acetyltransferase [8] and garlic has been shown to modulate the activities of transferases and CYP systems [16,17], garlic may have delayed the acetylation of INH which resulted in $41.28 \%$ increase in half life and the corresponding $50 \%$ decrease in its rate of clearance.

Our study on the effect of garlic on ciprofloxacin penetration into the lungs showed that garlic affected the penetration rate of ciprof- 
loxacin. From our data on the comparison of mean lung plasma Ciprofloxacin concentration [Table-3], there was no change in lung plasma ciprofloxacin concentration but, in lung fluid concentration comparison table [Table-4], ciprofloxacin peak concentration in the garlic treated group was higher than that obtained in the group that received ciprofloxacin alone. Secondly, the time to attain peak lung plasma concentration was delayed in the garlic treated group. The increased penetration of ciprofloxacin in the garlic treated group may likely be due to the inhibitory effect of garlic on P-glycoprotein [4] and on enzyme metabolizing activities of ciprofloxacin $[1,7]$ that will lead to increased ciprofloxacin concentration in the plasma. This increased plasma concentration will lead to increased penetration in to the tissues as a result of increased diffusion.

On the other hand, garlic had little or no effect on the extent of INH penetration into the lung tissues. However, garlic delayed the time to reach maximum concentration in garlic treated group. Though in the initial studies, garlic inhibited the metabolism of CYP450 enzymes and enhanced the absorption of ciprofloxacin and Isoniazid; their effects may have been of little or no significance to penetration effect. It has been shown that the organs and tissues have enzymes that metabolizes drugs (extraheptic metabolism) [18], but it has been shown that the effects of substances in inducing or inhibiting these enzymes might be very minimal [18].

Finally, our study also supported the fact that Isoniazid and ciprofloxacin have high tissue distribution with concentrations in lungs and kidney sometimes higher than in plasma [14].

\section{Conclusion}

Our results indicate that Allium sativum (Garlic) exhibited significant pharmacokinetic interaction with Ciprofloxacin and Isoniazid which resulted in increased bioavailability of the drugs. Therefore, concurrent use of the herb and the drugs may reduce the required dose of these drugs which may help in side effects/toxicity reduction of such drugs.

\section{Refernces}

[1] Piscitelli S.C., Burstein A.H., Welden N., Gallicano K. and Falloon J. (2002) Clin. Inf. Diseases, 34, 234-238.

[2] Samman S., Sandstrom B. and Toft M.B. (2001) Am. J. Clin. Nutr., 73, 607-12.

[3] Barnes J., Anderson L.A. and Phillipson J.D. (2002) Herbal Medicines, 2nd ed. London, 14.

[4] Ackermann R.T. (2001) Arch. Intern. Med., 161, 813-824.

[5] Mason P. (2001) Dietary, 2nd ed. London, 1-5.

[6] Foster B.C., Foster M.S. and Vandenhoek S. ( 2001) J. Pharm. Sci., 4, 176-84.

[7] Wu C.C., Sheen L.Y., Chen H.W., Kuo W.W., Tsai S.J. and Lii C.K. (2002) J. Agric. Food Chem., 50, 378-83.

[8] Martindale (2005) The Complete Drug Reference., London.

[9] Ofoefule S.I., Obodo C.E., Orasekwe O.E., llondu N.A., Afonne O.J., Maduka S.O., et al. (2001) Am. J. Ther., 8, 243-246.

[10]Microsoft Encarta Encyclopaedia (2009) Ciprofloxacin In.

[11]Eidus L. and Harnanansingh A.M.T. (1971) Clin. Chem., 17, 492-494.

[12]De U.K., Sinha K.P. and Banerjee N.C. (1993) Ind. J. Animal Sci., 65, 269-272.

[13]Gwilt P.R., Lear C.L., Tempero A.M., Birt D.D., Grandjean A.C., Ruddon R.W., et al. (1994) Cancer Epidemol-Biomarker Prev.,
3, 155-160.

[14]Kays M.B. Koda-Kimble M.A., Young L.Y., Alldredge B.K., Corelli R.L., Guglielino B.J., Kradjan W.A. and Williams B.R. (2009) The Clinical Use of Drugs, 9th ed. New York: Lippincott Willams and Wilkins., 61-1-24

[15]Zeng T., Zhang C., Song F., Han X. and Xie K. (2009) Human and Exp. Tox., 28(12), 177-783.

[16]Ameen M., Musthapa M.S., Abidi P., Ahmad I. and Rahman Q. (2003) Biochem. Mol. Tox., 17, 366-371.

[17]Ip C. and Lisk D.J. (1997) Nutr. Cancer, 28(2), 184-188.

[18]Kashuba A.D.M., Persky A.M. and Brouwer K.L.M. (2006) Lippincott Wilkins, USA, 122-157. 